\title{
Research on safety risk early warning of tunnel construction based on BIM and RFID Technology
}

\author{
Chen Yong ${ }^{1}$, He Xudong ${ }^{1}$, Lin Guojun ${ }^{2}$, Wu Ping ${ }^{3 *}$ \\ ${ }^{1}$ China Railway Construction Group Co., Ltd., 100040 Beijing, China \\ ${ }^{2}$ Ninghai Transportation Bureau,315600 Ningbo, China \\ ${ }^{3}$ School of Civil Engineering and Architecture, NingboTech University, 315100 Ningbo, China
}

\begin{abstract}
Due to the frequent occurrence of safety accidents in tunnel construction, it poses a great threat to property safety and the life safety of construction personnel. According to the classification of accident types, this paper standardizes the data of influential risk factors, delimits the boundary of dangerous areas, and proposes the specific steps of inputting field information into BIM database. The results show that the combination of BIM and RFID technology can monitor the conditions of the construction site in real time, and realize the automatic early warning of the dangerous sources in the tunnel construction.
\end{abstract}

\section{Introduction}

Underground engineering construction is a high-risk construction project with the characteristics of large investment, long cycle, complex technology, unpredictable risk factors and large impact on social environment[1]. Common tunnel accidents can be summarized into eight categories: fire and explosion accidents, tunnel collapse accidents, implement injury accidents, electric shock accidents, poisoning and asphyxiation accidents, falling accidents from high places and object striking accidents.

Building Information Modelling and Internet of Things are information technology developed by the country in recent years. BIM technology has the characteristics of integration and visualization[2], which is of great significance for improving engineering quality and efficiency, reducing cost, and realizing resource dynamics and sharing. Internet of Things technology can effectively monitor the construction site through wireless sensing, which can provide reliable data. Therefore, the combination of BIM and the Internet of Things can achieve the purpose of remote automatic monitoring and real-time early warning, hence reducing construction safety risks, reducing the occurrence of accidents, ensuring the safety of construction personnel and reducing economic losses.

By establishing tunnel construction safety risk early warning database, this study finally formed and constructed a tunnel construction safety early warning platform based on BIM and RFID.

\section{2 warning database for tunnel construction based on BIM and RFID}

RFID technology is used to mark the location of construction site and locate the dynamic location of operators. Through the real-time interaction between the collected data and BIM model data, the safety status information of personnel is dynamically analysed and early warning of dangerous status is provided. The early warning model needs to collect, process, filter, refine and judge the obtained information to determine whether the data value monitored by the security early warning platform is in a safe state. According to the types of tunnel accidents in 8 categories, the boundaries of dangerous areas are delineated for all kinds of dangerous sources in the construction of tunnel projects, which is the basis for early warning of safety risks.

\subsection{Establishment of Risk Source Database}

\subsubsection{Flammable gas concentration monitoring}

The accident caused by gas is the most common accident in tunnel construction explosion. Explosions must meet three basic conditions at the same time, one is the gas concentration, the other is an ignition source with sufficient energy, and the third is sufficient oxygen content. The critical gas concentration value in the tunnel is shown in Table 1.

\footnotetext{
${ }^{*}$ Corresponding author: wuping@nbt.edu.cn
} 
Table1. Critical value of gas concentration in tunnel.

\begin{tabular}{|c|c|}
\hline Concentration & Impact \\
\hline$<\mathbf{5 \%}$ & No explosion in case of fire \\
\hline $\mathbf{5 \% - 1 6 \%}$ & $\begin{array}{c}\text { Gas in the air can cause explosion } \\
\text { when it meets fire }\end{array}$ \\
\hline$>\mathbf{1 6 \%}$ & $\begin{array}{c}\text { No explosion in case of fire, but in } \\
\text { the air fire will still burn. }\end{array}$ \\
\hline
\end{tabular}

\subsubsection{Special geotechnical monitoring}

According to the statistical analysis of the accident, the tunnel collapse is the highest incidence and the more serious casualties of the accident, so the cause of the tunnel collapse needs to be paid attention to.

(1) Rock explosion

There are three conditions for rock explosion: (1) hard and complete rock; (2) highland stress; 3 rock of high fragility. The integrity of the rock directly determines whether a rock explosion will occur. The rock integrity coefficient $\mathrm{Kv}$ can be used as the criterion for determining the occurrence of rock explosion. In the initial ground stress grading of a rock body, the strength stress ratio $\mathrm{S}$ refers to the ratio of the rock's pressure strength to the ground stress[3]. The brittle coefficient B of rock can describe the brittleness of rock very well, reflect its tendency to occur rock explosion. The three conditions under which the integrated rock explosion occurred are summarized as shown in Table 2.

Table2. Early Warning for Rock Explosion.

\begin{tabular}{|c|c|c|}
\hline Condition & Outcome & Early warning \\
\hline $0.55<Q<0.75$ & \multirow{3}{*}{$\begin{array}{l}\text { Medium } \\
\text { to low } \\
\text { intensity }\end{array}$} & \multirow{3}{*}{$\begin{array}{l}\text { When any two of these values } \\
\text { meet the criteria. Yellow alert. }\end{array}$} \\
\hline $2.5 \leq \mathrm{S} \leq 5$ & & \\
\hline $3<B<5$ & & \\
\hline $\mathrm{Kv}>0.75$ & \multirow{3}{*}{$\begin{array}{l}\text { Severe } \\
\text { intensity }\end{array}$} & \multirow{3}{*}{$\begin{array}{l}\text { When any two of these values } \\
\text { meet the criteria. Red alert. }\end{array}$} \\
\hline $\mathrm{S}<2.5$ & & \\
\hline$B \geq 5$ & & \\
\hline
\end{tabular}

(2) Surrounding rock

Expansion, water-rich weak fracture, extrusion and other surrounding rocks are very easy to cause tunnel collapse, and the mechanics is the most affecting factors of rock stability, which refers to the surrounding rock resistance deformation and destruction performance. The level of surrounding rock is shown in Table 3 . There are six levels of surrounding rock, starting from IV level, surrounding rock may lose stability, resulting in a larger collapse, and after the accident, it was found that some tunnel collapse accidents, is due to the sudden change of surrounding rock from level III to $\mathrm{V}$, resulting in collapse. Therefore, with class III perimeter rock as the boundary, when the elastic vertical wave velocity of the surrounding rock $>3 \mathrm{~km} / \mathrm{s}$, it is considered a safe state, when velocity tends to be $3 \mathrm{~km} / \mathrm{s}$, it is considered unsafe.
Table3. Surrounding Rock Grading.

\begin{tabular}{|c|c|c|}
\hline Level & Stable state after excavation & $\begin{array}{c}\text { Kv } \\
\mathbf{( k m} / \mathbf{s})\end{array}$ \\
\hline I & Stable. & $>4.5$ \\
\hline II & $\begin{array}{c}\text { When exposed for a long time, local } \\
\text { slight collapse may occur. The side } \\
\text { wall is stable. }\end{array}$ & $3.5-4.5$ \\
\hline III & $\begin{array}{c}\text { When arch is not supported, slight } \\
\text { collapse may occur. The side wall is } \\
\text { basically stable. When the blasting } \\
\text { vibration is too large, collapse is } \\
\text { easy to occur. }\end{array}$ & $2.5-4.0$ \\
\hline IV & $\begin{array}{c}\text { When arch is not supported, serious } \\
\text { collapse may occur. The side walls } \\
\text { are sometimes unstable }\end{array}$ & $1.5-3.0$ \\
\hline VI & $\begin{array}{c}\text { Easy to collapse and deform. In the } \\
\text { presence of water, soil and sand } \\
\text { often gush out together with water. }\end{array}$ & $<1.0$ \\
\hline V & \begin{tabular}{c} 
Easy to collapse. \\
\hline
\end{tabular} & $1.0-2.0$ \\
\hline
\end{tabular}

\subsubsection{Toxic gas monitoring}

Toxic gas in tunnels has always been the main source of danger in the construction process, which is easy to cause poisoning or asphyxiation of major safety accidents. The main toxic gases are $\mathrm{CH}_{4}, \mathrm{CO}, \mathrm{CO}_{2}, \mathrm{H}_{2} \mathrm{~S}$ and $\mathrm{NH}_{3}$. The permissible concentration values of toxic gases commonly found in tunnels are shown in Table 4.

Table4. Allowed concentrations of common toxic gases in tunnels.

\begin{tabular}{|c|c|c|}
\hline $\begin{array}{c}\text { serial } \\
\text { number }\end{array}$ & $\begin{array}{c}\text { The name of } \\
\text { the harmful } \\
\text { gas }\end{array}$ & Limit concentration \\
\hline $\mathbf{1}$ & $\mathbf{C H}_{4}$ & $1 \%$ \\
\hline $\mathbf{2}$ & $\mathbf{C O}$ & $0.0024 \%$ \\
\hline $\mathbf{3}$ & $\mathbf{C O}_{2}$ & $1.5 \%$ \\
\hline $\mathbf{4}$ & $\mathbf{H}_{2} \mathbf{S}$ & $0.00066 \%$ \\
\hline $\mathbf{5}$ & $\mathbf{S O}_{2}$ & $0.0005 \%$ \\
\hline $\mathbf{6}$ & $\mathbf{N H}_{3}$ & $0.0004 \%$ \\
\hline $\mathbf{7}$ & $\mathbf{N O}_{2}$ & $0.0025 \%$ \\
\hline
\end{tabular}

\subsection{RFID requirements analysis}

\subsubsection{People related information collection}

Information about a person needs to be reflected by the worker wearing an RFID card with personal information. Its main information includes person identity information, personnel location information, and personnel status information.

Firstly, person identification information, including worker's name, blood type, emergency contact name and contact information. In addition, in order to ensure that the quality of workers meet the standards, RFID card should 
also record the safety of workers on-the-job production education and training and obtain the corresponding qualifications of induction certificate information. Person identification information is used both for clocking in at work and for personnel identification.

Secondly, personnel location information, construction personnel close to hazardous areas at different distances of the early warning results as shown in Table 5.

Table5. Early warning results for construction personnel near hazardous areas at different distances.

\begin{tabular}{|c|c|}
\hline $\begin{array}{c}\text { The location of } \\
\text { the person }\end{array}$ & Early warning information \\
\hline $\begin{array}{c}\mathbf{2 . 5 m} \text { from the } \\
\text { hazardous area }\end{array}$ & $\begin{array}{c}\text { The BIM module appears "yellow" } \\
\text { at the appropriate location and the } \\
\text { person icon flashes }\end{array}$ \\
\hline $\begin{array}{c}\mathbf{1 . 5 m} \text { from the } \\
\text { hazardous area }\end{array}$ & $\begin{array}{c}\text { "Orange" appears at the appropriate } \\
\text { location of the BIM module, and the } \\
\text { person icon flashes and alarms }\end{array}$ \\
\hline
\end{tabular}

Common tunnel accidents also include object blows, implement injuries, electric shocks, etc. According to the classification criteria, dangerous areas are defined. Take the collision zone and the electric shock zone as an example[4].

Collision zone. Unsafe factors in its construction may include mechanical equipment, etc. The mechanical equipment here refers to the construction machinery and transport vehicles at the construction site, etc., and when such machinery and equipment is in working condition, it is within $2 \mathrm{~m}$ of its outline as a collision zone

Electric shock zone. Unsafe factors in its construction may include wires or cables, etc. Therefore, the ribbon area of $1 \mathrm{~m}$ next to a wire or cable is defined as a electrocution zone.

Using the simulation property of BIM, a circular danger area with the location of the "object" as the center of the circle and the safety distance as the radius, namely the collision area and the electric shock area, is simulated, and the red color is displayed in the BIM platform. In addition, the radius of $1.5 \mathrm{~m}+$ safety distance $/ 2.5 \mathrm{~m}+$ safety distance in Table 6 above should be used to draw circular areas respectively and distinguish them with orange/yellow[5].

In addition, in addition to collisions between people and objects, there are collisions between objects and objects in the definition of collision zones, the mechanical installation of a cluster of travel, weight, inclination sensors, LCD hosts and video cameras equal to a cluster of tree-shaped wireless sensing network, for real-time dynamic monitoring[6].

Finally, personnel status information refers to the length and length of construction workers working hours, if the construction personnel excessive fatigue is very easy to cause safety accidents, through wearing RFID card to monitor workers working hours, timely adjustment.

\subsubsection{Information collection of objects}

"Objects" mainly refer to materials and machinery. In the tunnel construction process, the unsafe state of the material is also very easy to cause the occurrence of safety accidents. The security risk warning platform monitors the status of the relevant object equipment in real time, enters the relevant information of the "thing" into the RFID card, and guarantees that each "object" corresponds to an RFID card. Input information includes parameter information about materials and machinery, such as model number, date of manufacture, manufacturer, etc., as well as its location information and trajectory.

\section{Security management system construction}

Through the above research, an early warning platform for tunnel construction safety risks based on BIM technology and RFID technology is established. Including data collection, data processing and security alert three parts.

(1) Data collection

Data collection is used to obtain various unsafe data during construction. Various sources of hazards can be monitored and located using radio frequency identification (RFID) technology. In addition, the location information of personnel and mechanical targets can be dynamically monitored and the information of emergencies can be processed and analysed. Selforganizing and information collaboration with sensor networks enables close-up transmission of data from sensors, RFIDs, and other data collection devices. Environmentally aware information (stress, temperature, gas concentration, etc.) and the collected data are submitted to the monitoring host via a gateway in the data transmission subsystem.

(2) Data processing and transmission

Data processing is conducted based on LAN network and PAN network. After RFID tag scanning information is automatically transmitted to the BIM model through the network, the collected data is transmitted, filtered, checked, grouped, and the data is systematically managed. The risk data is interacted with the BIM model that passes the IFC standard, and the security status of the target location, surrounding environment, and stress level is finally presented through comparative analysis.

(3) Security alert

Safety early warning is used to collect various safety data on the construction site in order to realize the various functions of the platform. It is divided into analysis stage and monitoring stage, including BIM dynamic simulation, target dynamic monitoring, real-time safety analysis and early warning of construction process. Firstly, according to the results of the analysis stage, the monitoring object is set up, the tag type is defined, and the equipment and tags are set up. Secondly, during the construction process, the BIM model is used to track and locate the target visually; Finally, the monitoring process information is updated automatically to form BIM security information database. The project safety managers can obtain the safety information of the construction site in real time. The 
accuracy and real-time of safety early warning can be ensured by adding and correcting the safety information in time. The early warning system can also sends out early warning signals to safety managers and proposes safety solutions.

\section{Conclusion}

This paper uses information technology to realize realtime monitoring and early warning of safety risks in tunnel construction. A tunnel engineering security risk warning platform based on BIM and RFID technology is established, the demand data of the early warning platform is obtained according to the analysis of risk sources. The corresponding data standardization are formulated and embedded into the database. The platform is divided into data collection, processing transmission and security early warning subsystem, in which case, the three subsystems coordinate the work of the construction process unsafe people, objects, geological environment data collection and real-time monitoring. By transmitting the data to the BIM model in a timely manner and performing visual analysis, early warnings can be effectively and accurately issued to notify relevant personnel to take appropriate measures to ensure the safety of construction personnel.

\section{Acknowledgement:}

China Railway Construction Group Co., Ltd. Science and Technology Research and Development Project (2020-12), Ningbo Municipal Transportation Bureau Science and Technology Project (202007).

\section{Reference}

1. Q. H. Qian, R. X. Li, Journal of rock mechanics and engineering, 649-655(2008).

2. H. Q. Lv, Sichuan Cement, 120(2019).

3. L. D. Zhu, Shanxi architecture, 42, 176-177 (2016).

4. Y. L. Liu, Y. H. Chen, Y. L. Gao, Shanxi architecture, 45, 188-189(2019).

5. X. W. Zou, D. Zhang, H. Ma, Journal of engineering management, 33, 124-129(2019). 